\title{
Morfologia de plântulas de Leguminosae e o potencial sistemático
}

\author{
Leguminosae seedlings morphology and the systematic potential
}

\author{
Ely Simone Cajueiro Gurgel ${ }^{1,4}$, João Ubiratan Moreira dos Santos ${ }^{2}$, Flávia Cristina Araújo Lucas ${ }^{3}$ \\ \& Maria de Nazaré do Carmo Bastos ${ }^{1}$
}

\begin{abstract}
Resumo
As investigações sobre a morfologia de plântulas, antes do surgimento dos metafilos, têm demonstrado rico potencial para estudos sistemáticos, inclusive testando a monofilia de gêneros de Leguminosae. Além disso, proporcionam a descoberta de estruturas transitórias, basais ou derivadas, que podem estabelecer conexões nem sempre ocorrentes no indivíduo adulto. A natureza dos cotilédones, de reserva ou folíaceos, é uma das principais características das leguminosae. O tipo de germinação constitui um dos caracteres mais relevantes para diferenciar suas espécies, assim como a forma do limbo, da margem, do ápice, posição dos eofilos, presença ou ausência de látex ou resina, relação comprimento/largura dos cotilédones, tamanho e número de pinas, pecíolo alado ou não, que permitem caracterizar famílias, gêneros e até mesmo espécies. Em Leguminosae, a morfologia de plântulas corrobora a identificação das plantas no campo e ainda fornece subsídios para delimitações genéricas e infragenéricas na família. De uma maneira geral as plântulas de Caesalpinioideae e Mimosoideae são epígeas, com cotilédones foliáceos; em Papilionoideae predominam plântulas hipógeas com cotilédones de reserva e extremamente variadas em termos morfológicos, principalmente nas tribos com espécies lenhosas.
\end{abstract}

Palavras-chave: sistemática, blastogenia, habitat, morfologia de cotilédones.

\begin{abstract}
The study of seedling morphology, before metaphyll sprouting, is a powerful tool in systematic studies in order to help identify monophyletic genera of Leguminosae. The study of seedling morphology leads to the discovery of temporary, basal and derived structures that are helpful to establish phylogenetic relationships, but may not be present in the adult individual. Cotyledon type, foliaceous or reserve, is one of the most important species characteristics. It facilitates the understanding of important strategic evolutionary changes as well as the ecological and evolutionary history of species of plants in relation to their habitat. The type of germination constitutes one of the most important characteristics used to identify species. In addition, characteristics such as shape of the limbus, edge, apex, eophyll position, presence or absence of latex or resin, length/width relationship of cotyledons, size and number of pinnae, as well as petiole winged or not, allow the identification of families, genera or even species. In Leguminosae, the study of plant morphology is used to confirm plant identification in the field, as well as to delimit generic and infrageneric identification in this family. Overall, Caesalpinioideae and Mimosoideae seedlings are considered epigeal, with foliaceous-type cotyledons; on the other hand in the Papilionoideae there is a predominance of hypogeal species with reserve cotyledons. The latter has also great variety, especially in tribes with ligneous species.
\end{abstract}

Key words: sistematics, blastogeny, habitat, cotyledon morphology.

\section{Introdução}

Além do conhecimento morfológico das estruturas vegetativas e reprodutivas classicamente utilizadas na taxonomia, as características de sementes e da fase que precede a germinação até o completo desenvolvimento da planta jovem são subsídios que podem facilitar a identificação mais precisa das espécies, especialmente aquelas presentes nos ecossistemas florestais.

\footnotetext{
${ }^{1}$ Museu Paraense Emílio Goeldi, Av. Magalhães Barata 376, São Braz, CP 399, 66040-170, Belém, PA, Brasil. esgurgel@museu-goeldi.br

${ }^{2}$ Universidade Federal Rural da Amazônia, Instituto de Ciências Agrárias, Av. Pres. Tancredo Neves 2501, 66.077-901, Belém, PA, Brasil. bira@museu-goeldi.br.

${ }^{3}$ Universidade do Estado do Pará, Depto. Ciências Naturais, R. do Una 156, 66.113-200, Belém, PA, Brasil. copaldoc@yahoo.com.br.

${ }^{4}$ Autor para correspondência: esgurgel@museu-goeldi.br
} 
A demanda por manuais de identificação de plântulas é crescente, principalmente para fins de manejo e conservação. As plântulas de espécies florestais tropicais demonstram uma extraordinária diversidade morfológica, podendo variar de poucos milímetros a mais de um metro. Além disso, o arranjo, o tamanho relativo e o contraste entre a forma das folhas e dos cotilédones são muito variáveis dentro e entre diferentes táxons (Garwood 1995, 1996).

As investigações sobre a morfologia de plântulas, antes do surgimento dos metafilos, têm demonstrado rico potencial para estudos sistemáticos (Mendonça Filho 2002), inclusive testando a monofilia de gêneros de Leguminosae (Rodrigues 2005).

Estes estudos são considerados acumulativos, uma vez que para a obtenção de dados acerca da morfologia de famílias e gêneros é necessário investigar previamente todo o processo germinativo em um expressivo número de espécies, adicionando características típicas com valor diagnóstico (Ricardi 1996). Como potenciais resultados destacam-se a descoberta de estruturas transitórias, basais ou derivadas, que eventualmente não ocorrem no indivíduo adulto, mas que podem estabelecer conexões filogenéticas (Gifford \& Foster 1989).

O tamanho da semente, bem como a natureza morfofuncional dos cotilédones, que pode ser de reserva ou fotossintetizante, são as duas principais características presentes no início do ciclo de vida das plantas, as quais evoluíram em resposta às mudanças estratégicas que podem refletir a história ecológica e evolutiva das mesmas em relação à seus habitats (Zanne et al. 2005). Em função de sua importância observa-se entretanto que informações referentes aos tipos de germinação ainda são relativamente pouco conhecidas na família.

O primeiro e mais amplo estudo sobre plântulas foi realizado por de Candolle (1825), botânico pioneiro que utilizou as características das plântulas para delimitar tribos e gêneros em Leguminosae, apresentou uma distinção primária com relação ao tipo de cotilédones, e classificou-os como foliares (phyllolobées) e de reserva (sarcolobées).

A partir de então, poucos botânicos seguiram esta linha, como Guillaumin (1910) e Compton (1912), estudando respectivamente Burseraceae e Leguminosae. Somente após duas décadas, o interesse em utilizar as características das plântulas em estudos taxonômicos cresceu consideravelmente. Neste segundo período, Léonard (1957), Jacobs (1966) e Baudet (1974), em suas investigações, forneceram mais detalhes sobre blastogenia, ou estudo do desenvolvimento de plântulas.
Uma das pesquisas mais relevantes nesta área, considerada referência para a morfologia de plântulas tropicais, foi realizada por Duke $(1965,1969)$, com cerca de 200 espécies florestais de diferentes famílias botânicas de Porto Rico e do Canal do Panamá. Duke (1969) tratou o assunto de forma abrangente, definiu alguns termos e citou as características que deveriam ser observadas nas plântulas. Além disso, caracterizou diversas famílias com observações fundamentadas em pelo menos uma espécie. Neste trabalho o autor ressaltou a importância da investigação das sementes para a botânica sistemática e das plântulas para a identificação e reconhecimento das espécies no campo. Desde então diferentes levantamentos nesta área foram desenvolvidos em Leguminosae (Moreira \& Moreira 1996; Silva et al. 1998; Oliveira 2001; Mansano et al. 2004; Rodrigues \& Tozzi 2007a,b; 2008), abrangendo diferentes terminologias, avaliações e alcance para sistemática e filogenia do grupo.

\section{Terminologia}

A terminologia destinada aos estudos de plântulas foi estabelecida, principalmente, em função da morfologia e funcionalidade dos cotilédones, visando compreender as funções das estruturas morfológicas nos processos de desenvolvimento e estabelecimento das plantas.

Os principais e atuais tipos morfofuncionais de plântulas tiveram suas nomenclaturas e terminologias determinadas nos trabalhos realizados por Léonard (1957), Duke $(1965,1969), \mathrm{Ng}(1975,1978)$ e Vogel (1983), e adotados por Garwood (1983) e Miquel (1987), os quais utilizaram principalmente a exposição, posição, textura e função dos cotilédones durante o processo de germinação e estabelecimento do novo indivíduo.

Léonard (1957) conjugou as informações das diferentes posições dos cotilédones em relação ao nível do solo e observou ainda a ocorrência frequente de formas transitórias. Quando ocorria a elevação dos cotilédones acima do solo considerou emergência epígea e, quando havia o alongamento do epicótilo, acima da inserção do cotilédone, de modo que este permanecia soterrado, como hipógea.

A primeira classificação (Duke 1965), foi fundamentada, sobretudo, quanto à exposição ou não dos cotilédones após a germinação, na qual foram propostos os termos fanerocotiledonar (Fig. 1a) e criptocotiledonar (Fig. 1b), respectivamente. A ocorrência destas duas categorias está diretamente 

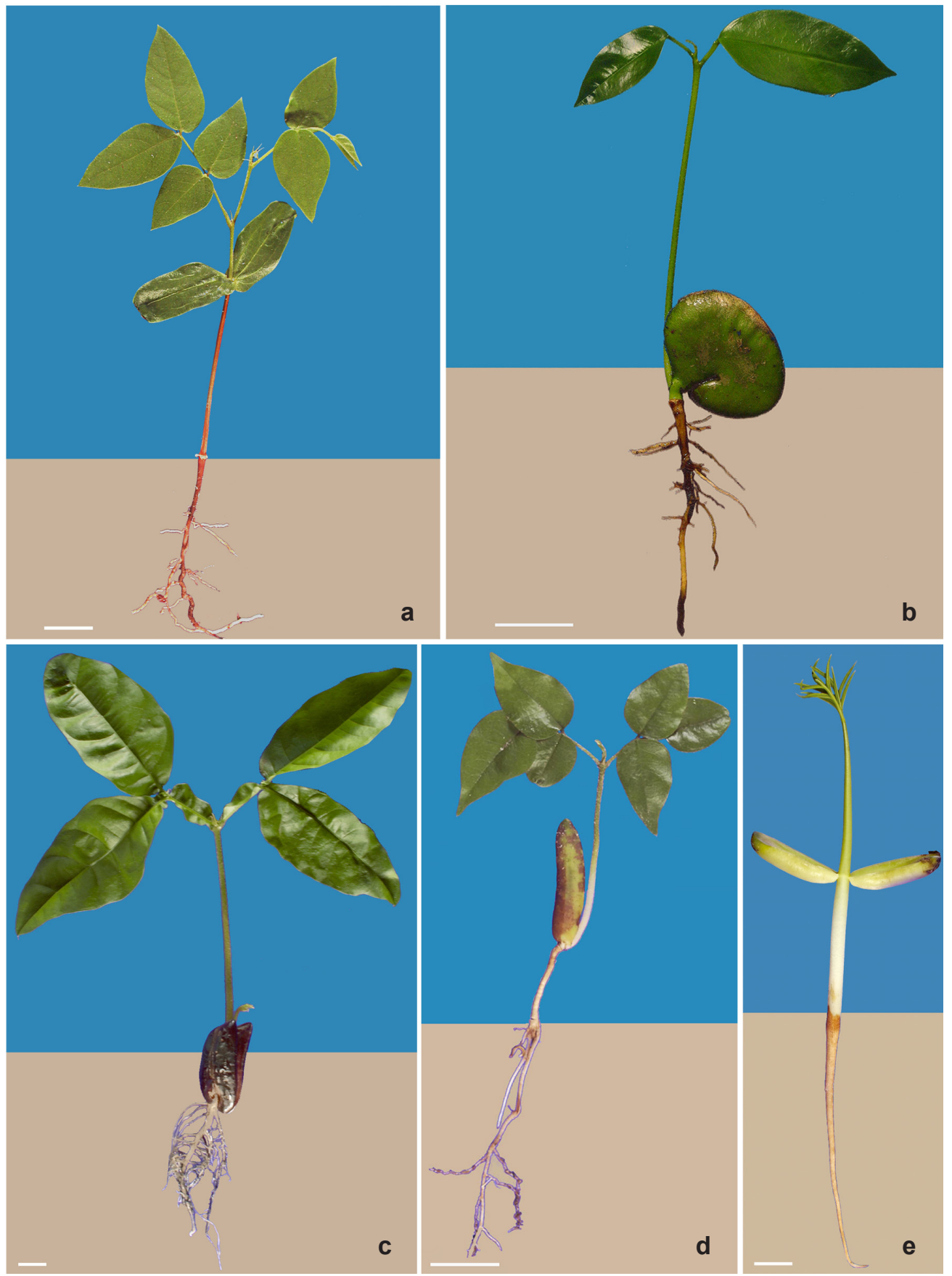

Figura 1 - Sistema de classificação morfofuncional de plântulas sensu Miquel (1987); a. Tipo 1 - fanerocotiledonar, epígeo, com cotilédones foliáceos (Tachigali vulgaris L.G.Silva \& H.C.Lima); b. Tipo 2 - fanerocotiledonar, epígeo, cotilédones de reserva (Dipteryx odorata (Aubl.) Willd.); c. Tipo 3 - fanerocotiledonar semi-hipógeo (Inga edulis Mart.); d. Tipo 4 - criptocotiledonar hipógeo (Diplotropis martiusii Benth.); e. Tipo 5 - criptocotiledonar epígeo (Diplotropis purpurea (Rich.) Amshoff). (barras =1 cm).

Figure 1 - Seedling classification system sensu Miquel(1987); a. Type 1 - phanerocotylar epigeal with foliaceous cotyledons (Tachigali vulgaris L.G.Silva \& H.C.Lima); b. Type 2 - phanerocotylar epigeal cotyledons reserve (Dipteryx odorata (Aubl.) Willd.); c. Type 3 - phanerocotylar hypogeal (Inga edulis Mart.); d. Type 4 - cryptocotyledonar hypogeal (Diplotropis martiusii Benth); e. Type 5 cryptocotyledonar epigeal (Diplotropis purpurea (Rich.) Amshoff.) (bars $=1 \mathrm{~cm})$. 
relacionada às condições ambientais, especialmente intensidade de luz e umidade.

Posteriormente, $\mathrm{Ng}$ (1975), estudando espécies arbóreas que ocorrem na Malásia, observou que o comprimento do hipocótilo é independente da exposição ou não dos cotilédones. $\mathrm{O}$ referido autor verificou ainda a necessidade de conjugar os termos fanerocotiledonar e criptocotiledonar, propostos por Duke (1965), aos termos epígeo e hipógeo, que foram nomeados de acordo com alongamento ou não do hipocótilo. Ng (1978), além dos termos já propostos, adicionou a nomenclatura semi-hipógea (Fig. 1c) para plântulas com cotilédones expostos, porém localizados no nível do solo e passou a adotar o termo durio para as plântulas criptocotiledonares epígeas (Fig. 1d), evitando assim modificar a nomenclatura já estabelecida.

Vogel (1983), ao estudar plântulas de espécies da Malásia, combinou as características morfológicas das sementes e incluiu a natureza dos cotilédones como foliáceos, frequentemente delgados, verdes e fotossintetizantes (Fig. 1a), ou carnosos, normalmente espessos, funcionando como órgãos de reserva, sendo ou não fotossintetizantes (Fig. 1e), bem como considerou as fases de repouso durante o desenvolvimento da plântula e a filotaxia dos eofilos.

O sistema sensu Miquel (1987) (Fig. 1) reuniu os sistemas de classificação de $\mathrm{Ng}$ (1978), Vogel (1983) e Garwood (1983) e possibilitou as comparações entre os estudos sobre ecologia morfofuncional de plântulas tropicais (IbarraManríquez et al. 2001; Marques 2002; Ressel et al. 2004). O sistema sensu Miquel (1987) compreende cinco tipos morfofuncionais de plântulas: fâneroepígeo-foliáceo (PEF), fânero-epígeo-armazenador (PER), fânero-hipógeo-armazenador (PHR), criptohipógeo-armazenador (CHR) e cripto-epígeoarmazenador (CER), terminologia, esta, proveniente do trabalho de Garwood (1995).

Duke \& Polhill (1981), ao revisarem a nomenclatura para Leguminosae, adotaram a terminologia de $\mathrm{Ng}$ (1975), descrevendo e ilustrando os seguintes tipos de plântulas: faneroepígea com cotilédones foliáceos e eofilos alternos, sendo o primeiro eofilo unifoliolado (Fig. 2a); faneroepígea com cotilédones armazenadores, com os dois primeiros eofilos opostos e unifoliolados (Fig. $2 b$ ); criptohipógea, cotilédones armazenadores e no nível do solo, primeiros eofilos pinados e o segundo bipinado com um par de pinas (Fig. 2c) e criptohipógea, com cotilédones armazenadores e abaixo do nível do solo, com muitos catafilos abaixo do eofilo trifoliolado (Fig. 2d).

\section{Caracteres relevantes para a sistemática}

O tipo de germinação constitui um dos caracteres mais relevantes para diferenciar espécies, enquanto o conhecimento morfológico da plântula, especialmente a forma do limbo, da margem, do ápice, posição dos eofilos, presença ou ausência de látex ou resina, relação comprimento/ largura dos cotilédones, tamanho das pinas, número de pinas, pecíolo alado ou não, presença ou não de indumento (tricomas e/ou glândulas), permitem caracterizar famílias, gêneros e até mesmo espécies (Duke 1965), e tem sido aplicado no inventário florestal de muitas regiões de clima temperado e tropical. Tais estudos, além das descrições e ilustrações, são acompanhados por chaves de identificação. Esses trabalhos têm fornecido informações valiosas sobre a morfologia, germinação, habitat e identificação de muitas espécies em fase juvenil (Oliveira 1993).

Duke \& Polhill (1981) realizaram amplo estudo sobre plântulas de Leguminosae, no que concerne à terminologia, ecologia e aplicação taxonômica. Os autores ressaltaram que a morfologia de plântulas contribui para identificação das plantas no campo e ainda para delimitações genéricas e infragenéricas na família, o que também foi verificado por diversos autores, dentre o quais se pode citar Léonard (1957), Vogel (1983), Nozzolillo (1985), Lima (1990), Oliveira (1993), Oliveira (1997), Oliveira \& Beltrati (1992), Nemoto \& Ohashi (1993), Ricardi (1996), Lopez et al. (1998), Silva \& Matos (1998), Oliveira (1999, 2001), Mendonça Filho (2002), Rodrigues (2005), Rodrigues \& Tozzi (2007a, b; 2008).

Pesquisas indicam que as plântulas de Caesalpinioideae e de Mimosoideae são epígeas, com cotilédones foliáceos, enquanto nas Papilionoideae predominam espécies com plântulas hipógeas, com cotilédones carnosos de morfologia extremamente variada, principalmente nas tribos com espécies lenhosas (Gates 1951). Em Tephrosieae, é comum o primeiro eofilo ser unifoliolado, tendência que se estende a algumas tribos mais derivadas, como em Phaseoleae, as quais podem ser fanerocotiledonares ou criptocotiledonares, porém, sempre com cotilédones carnosos e os primeiros eofilos opostos e unifoliolados (Duke \& Polhill 1981; Polhill et al. 1981). 
Oliveira (2001) também constatou que a morfologia das plântulas e plantas jovens demonstra a grande variação existente entre as tribos de Papilionoideae, citando ainda a necessidade de estudos com mais espécies, especialmente abordando ambientes específicos.

As Leguminosas têm expressiva ocorrência na Amazônia, muitas vezes predominando em relação às demais famílias, e isto tem sido constatado nos diversos levantamentos florísticos realizados, especialmente nas florestas da região. No caso das espécies arbóreas e de grande porte, as plântulas têm sido um recurso adicional confiável para identificação no campo, já que nem sempre dispõe-se de meios para coletar ramos com flores e/ou frutos.

Oenfoque taxonômico da morfologia de plântulas de espécies amazônicas começou com as descrições feitas por Lee \& Langenheim (1975) na revisão de Hymenaea L. (Leguminosae Caesalpinioideae). Os autores, separaram os táxons em dois grupos, em função da morfologia das plântulas e ocupação de um determinado ambiente e concluíram que os grupos ecológicos, quando correlacionados com outros caracteres, são úteis para um melhor entendimento da história evolutiva do grupo.
Posteriormente, a morfologia de plântulas foi referida em outras revisões, que também abrangeram táxons amazônicos, como as de Virola Aubl. (Myristicaceae), de Rodrigues (1980), Dimorphandra Schott. (Leguminosae Caesalpinioideae) de Silva (1986) e Lecythidaceae, na qual Mori \& Prance (1990) descreveram e ilustraram plântulas de Gustavia augusta L., Couratari stellata A.C. Sm., Bertholletia excelsa Bonpl. e Lecythis minor Jacq.

Mendonça-Filho (2002), ao agrupar as espécies de acordo com o desenvolvimento do eixo embrionário, número de pínulas na plúmula, tipo de plântula e número de folíolos do primeiro nó eofilar, constatou que essas características contribuem parcialmente com a sistemática das espécies e seções. O referido autor ressaltou que esses dados possibilitaram a inclusão de espécies ainda não classificadas e a transferência de outras espécies entre seções, permitindo além do refinamento dos estudos sistemáticos infragenéricos, a delimitação de espécies anteriormente tratadas como sinônimos, como Machaerium triste Vogel e M. brasiliense Vogel, e também M. aculeatum Raddi, M. hirtum (Vell.) Stellfeld e M. sericiflorum Vogel.
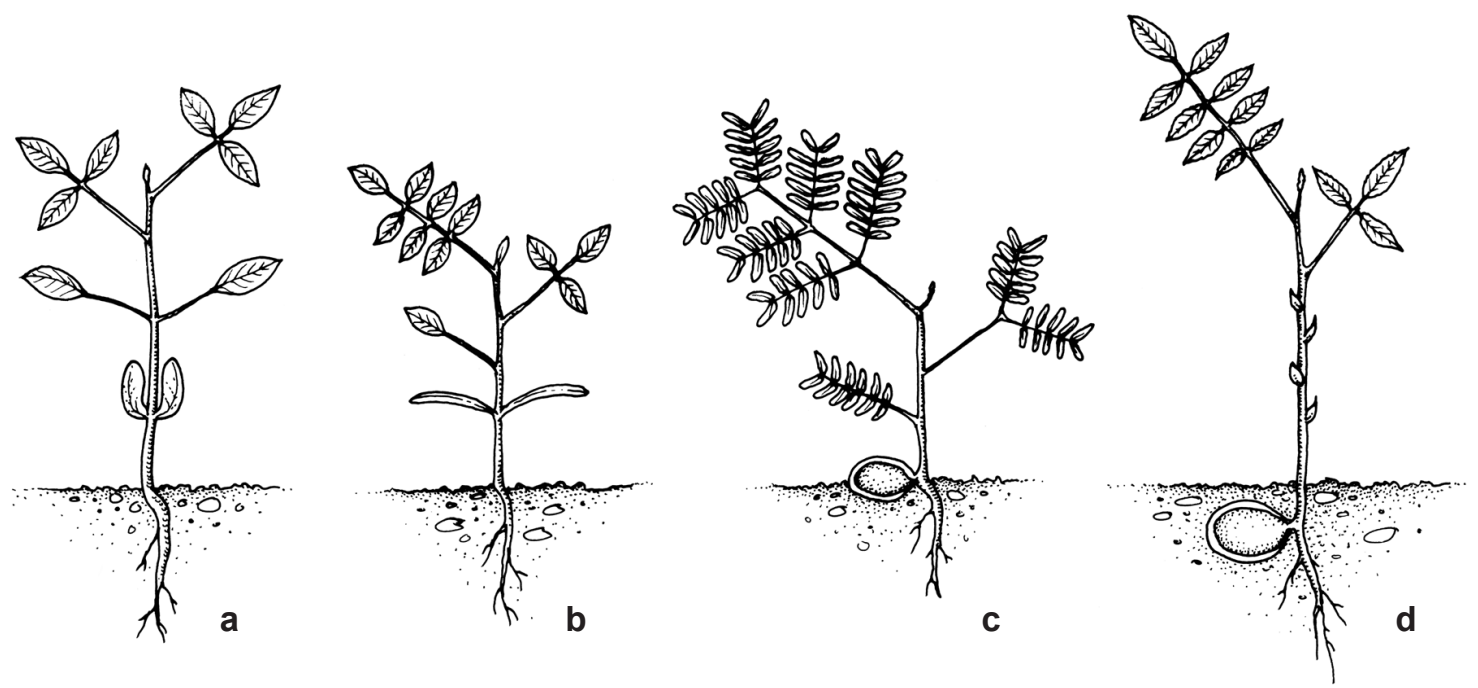

Figura 2 - Terminologia adotada por Duke \& Polhill (1981) para a família Leguminosae - a. faneroepígea com cotilédones foliáceos e eofilos alternos, sendo o primeiro eófilo unifoliolado; b. faneroepígea com cotilédones armazenadores, com os dois primeiros eófilos opostos e unifoliolados; c. criptogea, cotilédones armazenadores e no nível do solo, primeiros eófilos pinados e o segundo bipinado com um par de pinas; $d$. criptohipogea, com cotilédones armazenadores e abaixo do nível do solo, com muitos catáfilos abaixo do eófilo trifoliolado.

Figure 2 - Duke \& Polhill (1981) seedling terminology to the Leguminosae - a. phaneroepigeal with foliar cotyledons and alternate eophylls, with the first eophyll unifoliolate; b. phaneroepigeal with clasping storage cotyledons, the first two eophylls opposite and unifoliolate; c. cryptogeal with first eophyll pinnate, the second alternate and bipinnate; d. criptohypogeal, estorage cotyledons below the grounde level, with several cataphylls below the trifoliolate eophyll. 
Mais recentemente, Martins-da-Silva (2006) revisando os representantes de Copaifera L. da Amazônia brasileira, observou que, de acordo com a classificação de Miquel (1987), Copaifera glycycarpa Ducke, C. duckei Dwyer, C. martii Hayne, C. multijuga Hayne, C. pubiflora Benth. e C. reticulata Ducke apresentam germinação fanerocotiledonar epígea, com cotilédones carnosos. Registrou ainda eofilos opostos em $C$. duckey e C. reticulata, porém Léonard (1957) baseado apenas em $C$. officinalis L., generalizou a presença de eofilos alternos para todas as Copaifera do continente americano.

Gurgel (2009) constatou que os caracteres morfológicos de plântulas constituíram dados seguramente válidos para a delimitação das espécies de Copaifera. A presença de estípulas foliáceas conspícuas em $C$. reticulata foi o caráter preponderante para distingui-la de Copaifera martii e C. duckei. A referida autora ressaltou que o número de folíolos, utilizado como característa diagnóstica para separar $C$. duckei de C. reticulata na fase adulta, não são válidos na fase de plântulas.

Rodrigues \& Tozzi (2007a), com o objetivo de constatar a relevância e ampliar o conhecimento sobre a morfologia de plântulas de representantes arbóreos brasileiros, do clado Genistóide (Leguminosae - Papilionoideae), descreveram, ilustraram e compararam as estruturas presentes nas plântulas. Também, verificaram que a filotaxia oposta dos eofilos de Diplotropis martiusii Benth. a distingue de Diplotropis purpurea (Rich.) Amshoff.

Ao analisar o clado Vatairea (Leguminosae - Papilionoideae), composto pelos gêneros Luetzelburgia Harms, Sweetia Spreng., Vatairea Aublet e Vataireopsis Ducke, sensu Mansano et al. (2004), estes autores observaram plântulas fanero-epígeo-armazenadoras em Luetzelburgia guaissara Toledo e cripto-hipógeo-armazenadoras em Sweetia fruticosa Spreng. Rodrigues \& Tozzi (2007b) apresentaram uma breve revisão da morfologia de plântulas dos representantes do clado Vatairea, bem como uma chave de plântulas para a identificação de seus gêneros e constataram que a variação dos tipos morfológicos e do número de folíolos, presença de catafilos, projeção basal no colo e tipo de nictinastia foliolar são sistematicamente relevantes para a distinção de gêneros neste clado.

Plântulas de algumas espécies de Acosmium Schott, Leptolobium Vogel e Guianodendron Sch. Rodr. \& A. M. G. Azevedo foram descritas por Rodrigues \& Tozzi (2008), para subsidiar a distinção taxonômica entre estes gêneros. Esses autores verificaram que Guianodendron tem plântulas criptohipógeas com cotilédones de reserva, enquanto as plântulas de Acosmium e Leptolobium são fanerocotiledonar epígeas, com cotilédones foliáceos, sendo que estes dois últimos gêneros são diferentes entre si, principalmente, devido à forma do hipocótilo, a razão entre o comprimento do hipocótilo/epicótilo, nictinastia dos folíolos e cotilédones, forma e venação dos cotilédones, estípula e morfologia dos folíolos, presença ou ausência de glândulas intercotiledonares, e em outras partes vegetativas. Os autores concluiram que os dados da morfologia da plântula são caracteres de relevante valor sistemático e apoiam as mudanças propostas na delimitação genérica de Acosmium.

Os trabalhos de Silva et al. (1988) e de Albuquerque $(1987,1993)$ são referências para os estudos morfológicos de sementes e plântulas da Amazônia, sendo que Albuquerque (1993) descreveu e ilustrou detalhadamente 20 espécies florestais e 30 invasoras de culturas.

Outros estudos ampliaram o conhecimento sobre a morfologia de plântulas de leguminosas amazônicas, como os de Gurgel (2000), Ferreira et al. (2001), Melo (2001), Gurgel et al. (2002), Embrapa Amazônia Oriental (2004a,b,c,d,e,f), Melo et al. (2004), Melo \& Varela (2006), Camargo et al. (2008), Ramos \& Ferraz (2008) e Gurgel (2009). Destacam-se por fim os trabalhos com a espécie amazônica Copaifera multijuga Hayne (Alencar 1981; Moreira \& Moreira 1996; Brum et al. 2007).

\section{Referências}

Albuquerque, J.M. 1987. Estudo morfológico da semente e sua germinação até a fase de plântula, principalmente de plantas invasoras de culturas $\mathrm{e}$ de essências florestais da Amazônia. Dissertação de Mestrado. Universidade Federal do Amazonas, Instituto Nacional de Pesquisas da Amazônia, Manaus. 137p.

Albuquerque, J.M. 1993. Identificação e germinação de sementes amazônicas. FCAP. Serviço de Documentação e Informação. 132p.

Alencar, J. C. 1981. Estudos silviculturais de uma população natural de Copaifera multijuga Hayne Leguminosae, na Amazônia Central. 1 - Germinação. Acta Amazonica 11: 3-11.

Baudet, J.C. 1974. Signification taxonomique dês caracteres blastogéniques dans la tribu des Papilionaceae- 
Phaseoleae. Bulletin du Jardin Botanique National de Belgique. 44: 259-293.

Brum, H.D.; Mesquita, M.R. \& Ferraz, I.D.K. 2007. Descrição comparativa dos propágulos e plântulas de Copaifera multijuga Hayne e C. officinalis Jacq. (Fabaceae). Revista Brasileira de Biociências 5: 351-353.

Camargo, J.L.C.; Ferraz, I.D.K; Mesquita, M.R.; Santos, B.A. \& Brum, H.D. 2008. Guia de propágulos e plântulas da Amazônia. Vol. I. INPA, Manaus. 168p.

Candolle, A.P. 1825. The leguminous seed. Phytomorphology 1: 117-150.

Compton, R.H. 1912. An investigation of the seedling structure in the Leguminosae. Journal of the Linnean Society of London Botany 41: 1-122.

Duke, J.A. \& Polhill, R.M. 1981. Seedlings of Leguminosae. In: Polhill, R.M. \& Raven, P.H. (eds.). Advances in legumes systematics. Royal Botanic Gardens, Kew Part 1: 941-949.

Duke, J.A. 1965. Keys for the identification of seedlings of some proeminent woody species in eight forest types in Puerto Rico. Annals of the Missouri Botanical Garden 52: 314-350.

Duke, J.A. 1969. On tropical tree seedlings, systems and systematics. Annals of the Missouri Botanical Garden 56: 135-161.

EMBRAPA Amazônia Oriental. 2004a. Angelimvermelho, Dinizia excelsa Ducke. Embrapa Amazônia Oriental, Belém, Pará, Projeto Dendrogene, Espécies Arbóreas da Amazônia 6.

EMBRAPA Amazônia Oriental. 2004b. Cumaru, Dipteryx odorata (Ducke). Embrapa Amazônia Oriental, Belém, Pará, Projeto Dendrogene, Espécies Arbóreas da Amazônia 7.

EMBRAPAAmazônia Oriental. 2004c. Jatobá, Hymenaea courbaril L.. Embrapa Amazônia Oriental, Belém, Pará, Projeto Dendrogene, Espécies Arbóreas da Amazônia 8.

EMBRAPA Amazônia Oriental. 2004d. Timborana, Pseudopiptadenia psilostachya (DC) G.P.Lewis \& M.P.Lima. Embrapa Amazônia Oriental, Belém, Pará, Projeto Dendrogene, Espécies Arbóreas da Amazônia 9.

EMBRAPA Amazônia Oriental. 2004e. Visgueiro, Parkia pendula (Willd.) Benth. Ex Walp.. Embrapa Amazônia Oriental, Belém, Pará, Projeto Dendrogene, Espécies Arbóreas da Amazônia 10.

EMBRAPA Amazônia Oriental. 2004f. Fava-atanã, Parkia gigantocarpa Ducke. Embrapa Amazônia Oriental, Belém, Pará, Projeto Dendrogene, Espécies Arbóreas da Amazônia 11.

Ferreira, R. A.; Botelho, S. A.; Davide, A. C. \& Malavasi, M.M. 2001. Morfologia de frutos, sementes, plântulas e plantas jovens de Dimorphandra mollis
Benth. - faveira (Leguminosae-Caesalpinioideae). Revista Brasileira de Botânica 24: 303-309.

Garwood, N.C. 1983. Seed germination in a seasonal tropical forest in Panama: a community study. Ecological Monographs 53: 159-181.

Garwood, N.C. 1995. Studies in Annonaceae XX. Morphology and ecology of seedlings, fruits and seeds of selected Panamanian species. Botanische Jahrbücher für Systematik 117: 1-152.

Garwwod, N.C. 1996. Functional morphology of tropical tree seedlings. In: Swaine, M.D. (ed.). The ecology of tropical forest tree seedlings man and the biosphere. Vol. 18. Parthenon Publishing Group, New York. Pp. 59-129.

Gates, R.R. 1951. Epigeal germination in the Leguminosae. Botanical Gazette 113: 151-157.

Gifford, E.M. \& Foster, A.S. 1989. Morphology and evolution of vascular plants. 3rd ed. W.H. Freeman, New York. 626.p.

Guillaumin, A. 1910. Rechechers sur la structure et le développement sur Burséracées, aplication à la systématique.. Thèse. Faculté des Sciences de Paris, sér. A. No. 620. Masson, Paris.100 p.

Gurgel, E. S. C. 2000. Morfologia de frutos, sementes, germinação e plântulas de leguminosas presentes em uma vegetação de mata secundária na Amazônia Central. Dissertação de Mestrado. Instituto Nacional de Pesquisas da Amazônia, Universidade Federal do Amazonas, Manaus. $160 p$.

Gurgel, E.S.C. 2009. Morfoanatomia, perfil químico e atividade alelopática de três espécies de Copaifera L. (Leguminosae Caesalpinioideae) nativas da amazônia. Tese de Doutorado. Instituto Nacional de Pesquisas da Amazônia, Universidade Federal do Amazonas, Manaus. 107p.

Gurgel, E.S.C; Silva, M.F. \& Carreira, L.M.M. 2002. Morfologia do fruto, da semente e da plântula de Calopogonium mucunoides Desv. e Dipteryx odorata (Aubl.) Willd. (Leguminosae, Papilionoideae). Boletim do Museu Paraense Emílio Goeldi Série Botânica 18: 37-60.

Ibarra-Manríquez, G.; Ramos, M.M. \& Oyama, K. 2001. Seedling functional types in a lowland rain forest in Mexico. American Journal of Botany 88: 1801-1812.

Jacobs, M. 1966. The study of seedlings. Flora Malesiana Bulletin 21: 1416-1421

Lee, Y. \& Langenheim, J.H. 1975. Systematics of the genus Hymenaea L. (Leguminosae, Caesalpinioideae, Detarieae). University of California Publications in Botany 69: 18-20.

Léonard, J. 1957. Genera des Cynometreae et des Amherstieae africaines (Leguminosae Caesalpinioideae). Essai de blastogénie appliquée à la systématique. Memoire couronné par la Classe 
des Sciences de l' Académie Royale de Belgique. Sciences 30: 312 .

Lima, H.C. 1990. Tribo Dalbergieae (Leguminosae Papilionoideae): morfologia dos frutos, sementes e plântulas e sua aplicação na sistemática. Arquivo do Jardim Botânico do Rio de Janeiro 30: 1-42.

López, J.; Devesa, J.A.; Ruiz, T. \& Ortega-Olivencia, A. 1998. Seedling morphology in Genisteae (Fabaceae) from south-west Spain. Botanical Journal of the Linnean Society 127: 229-250.

Mansano, V.F.; Bittrich, V.; Tozzi, A.M.G.A. \& Souza, A.P. 2004. Composition of the Lecointea clade (Leguminosae, Papilionoideae, Swartzieae), a reevaluation based on combined evidence from morphology and molecular data. Taxon 53: 1007-1018.

Marques, M.C.M. 2002. Dinâmica da dispersão de sementes e regeneração de plantas da planície litorânea da Ilha do Mel, PR. Tese de Doutorado, Universidade Estadual de Campinas, Campinas. 145pp.

Martins-da-Silva, R.C.V. 2006. Taxonomia das espécies de Copaifera L. (Leguminosae Caesalpinoideae) ocorrentes na Amazônia brasileira. Tese de Doutorado. Universidade Federal do Rio de Janeiro, Rio de Janeiro. 258p.

Melo, M.G.G. 2001. Análise morfológica de sementes, germinação e plântulas de cinco espécies arbóreas utilizadas em Sistemas Agroflorestais na Amazônia. Dissertação de Mestrado. Universidade Federal do Amazonas, Manaus. 111p.

Melo, M.G.G.; Mendonça, M.S. \& Mendes, A.M.S. 2004. Análise morfológica de sementes, germinação e plântulas de jatobá (Hymenaea intermedia Ducke var. adenotricha (Ducke) Lee \& Lang.) (Leguminosaecaesalpinioideae). Acta Amazonica 34: 9-14.

Melo, M.F.F. \& Varela, V.P. 2006. Aspectos morfológicos de frutos, sementes, germinação e plântulas de duas espécies florestais da Amazônia. I. Dinizia excelsa Ducke (Angelim pedra). II Cedrelinga catenaeformis Ducke (cedrorana) - Leguminosae: Mimosoideae. Revista Brasileira de Sementes 28: 54-62.

Mendonça Filho, C.V.2002. Citotaxonomia de Machaerium Pers. e revisão taxonômica de Machaerium sect. Oblonga (Benth.) Taub. (LeguminosaePapilionoideae). Tese de Doutorado. Universidade Estadual de Campinas, Campinas. 207p.

Miquel, S. 1987. Morphologie fonctionelle de plantules d'especes forestières Du Gabon. Bulletin Muséum National d'Histoire Naturelle, serie 4, Section B, Adansônia Botanique Phytochimie 9: 101-121.

Moreira, F.M.S. \& Moreira, F.W. 1996. Características da germinação de sementes de 64 espécies de leguminosas florestais nativas da Amazônia, em condições de viveiro. Acta Amazonica 26: 3-16.

Mori, S.A. \& Prance, G.T. 1990. Lecythidaceae Part II: the zygomorphic-flowered New World Genera (Couroupita, Corythophora, Bertholletia, Couratari, Eschweilera, \& Lecythis). With a study of the secondary xylem of Neotropical Lecythidaceae by Carl de Zeeuw. Flora Neotropica 21: 1-376.

Nemoto, T. \& Ohashi, H. 1993. Seedling morphology of Lespedeza (Leguminosae). Journal of Plant Research 106: 121-128.

Ng, F.S.P. 1975. The fruits, seeds and seedlings of Malayan forest trees I-XI. Malaysian Forester. 38: 33-39.

Ng, F.S.P. 1978. Strategies of establishment in Malayan forest trees. In: Tomlinson, P.B.P. \& Zimmermann, M.H.(eds.). Tropical trees as living systems. Cambridge University Press, London. Pp. 129-162.

Nozzolillo, C. 1985. Seedling morphology and anatomy of eight Cicer species and their taxonomic value. Canadian Journal of Botany 63: 1-6.

Oliveira, D.M.T. 1997. Análise morfológica comparativa de frutos, sementes, plântulas e plantas jovens de 30 espécies arbóreas de Fabaceae ocorrentes no estado de São Paulo. Tese de Doutorado. Rio Claro. Universidade Estadual Paulista. 212p.

Oliveira, D.M.T. 1999. Morfologia de plântulas e plantas jovens de 30 espécies arbóreas de Leguminosae. Acta Botanica Brasilica 13: 263-269.

Oliveira, D.M.T. 2001. Morfologia comparada de plântulas e plantas jovens de leguminosas arbóreas nativas: espécies de Phaseoleae, Sophoreae, Swartzieae e Thephrosieae. Revista Brasileira de Botânica 24: 85-97.

Oliveira, D.M.T. \& Beltrati, C.M. 1992. Morfologia e desenvolvimento das plântulas de Inga fagifolia e I. urugüensis. Turrialba 42: 306-313.

Oliveira, E.C. 1993. Morfologia de plântulas florestais. In: Aguiar, I.B.; Piña-Rodrigues, F.C.M. \& Figliola, M.B. (eds.). Sementes florestais tropicais. ABRATES, Brasília. Pp. 175-214.

Polhill, R.M., Raven, P.H. \& Stirton, C.H. 1981. Evolution and systematics of the Leguminosae. In: Polhill, R.M. \& Raven, P.H. (eds.). Advances in legumes systematics. Royal Botanic Gardens, Kew Part 1: 1-26.

Ramos, M.B.P. \& Ferraz, I.D.K. 2008. Estudos morfológicos de frutos, sementes e plântulas de Enterolobium schomburgkii Benth. (LeguminosaeMimosoideae). Revista Brasileira de Botânica 31: 227-235.

Ressel, K.; Guilherme, F.A.G.; Schiavini, I. \& Oliveira, P. E.. 2004. Ecologia morfofuncional de plântulas de espécies arbóreas da Estação Ecológica do Panga, Uberlândia, Minas Gerais. Revista Brasileira de Botânica 27: 311-323.

Ricardi, M.; 1996. Morfologia de los cotiledones de plántulas de algunas familias o géneros presentes em Venezuela como fuente de caracteres para su determinación. Plantula 1: 1-11.

Rodrigues, R.S. 2005. Sistemática de Acosmium L. (Leguminosae, Papilionoideae, Sophoreae) 
estudos de morfologia de plântulas e números cromossômicos. Tese de Doutorado. Universidade Federal de Campinas, Campinas. $151 \mathrm{p}$.

Rodrigues, R.S.; Tozzi, A.M.G. A. 2007a. Morfologia de plântulas de cinco leguminosas genistóides arbóreas do Brasil (Leguminosae-Papilionoideae). Acta Botanica Brasilica 21: 599 - 607.

Rodrigues, R.S. \& Tozzi, A.M.G.A. 2007b. Morfologia de plântulas no clado Vatairea (Leguminosae, Papilionoideae). Rodriguésia 58: 221-229.

Rodrigues, R.S. \& Tozzi, A.M.G.A. 2008. Systematic relevance of seedling morphology in Acosmium, Guianodendron, and Leptolobium (Leguminosae, Papilionoideae). Brittonia 60: 287-296.

Rodrigues, W.A. 1980. Revisão taxonômica das espécies de Virola Aublet (Myristicaceae) do Brasil. Acta Amazonica 10: 1-127.
Silva, L.M.M. \& Matos, V.P. 1998. Morfologia de frutos, sementes e plântulas de catingueira (Caesalpinia pyramidalis Tul. - Caesalpinaceae) e de juazeiro (Zizyphus joazeiro Mart. - Rhamnanaceae). Revista Brasileira de Sementes 20: 25-31.

Silva, M.F. 1986. Dimorphandra (Caesalpiniaceae). Flora Neotropica. New York Botanical Garden 44: 126.

Silva, M.F.; Goldman, G.H.; Magalhães, F.M. \& Moreira, F.W. 1988. Germinação natural de 10 espécies arbóreas da Amazônia - I. Acta Amazonica 18: 9-26.

Vogel, E.F. 1983. Seedlings of dicotyledones. Pudoc, Wageningen. 465p.

Zanne, A.E.; Chapman, C.A. \& Kitajima, K. 2005. Evolutionary and ecological correlates of early seedling morphology in East African trees and shrubs. American Journal of Botany 92: 972-978. 